\title{
REVISED A fruit fly model for studying paclitaxel-induced
}

\section{peripheral neuropathy and hyperalgesia [version 2; peer}

\section{review: 2 approved, 1 approved with reservations]}

Previously titled: A fruit fly model for studying paclitaxel-induced pain

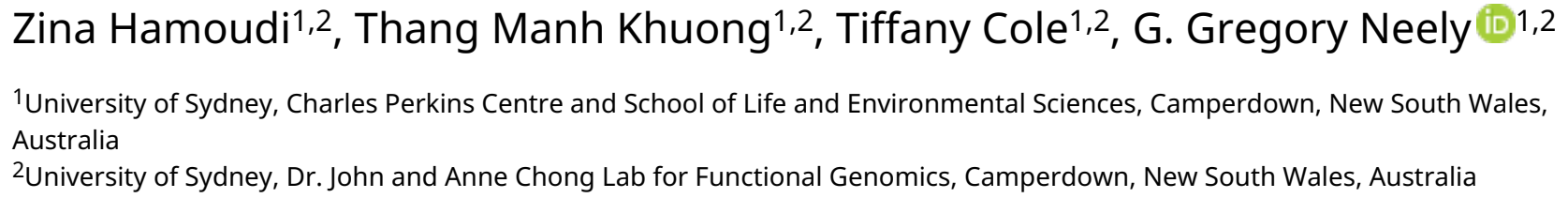

${ }^{1}$ University of Sydney, Charles Perkins Centre and School of Life and Environmental Sciences, Camperdown, New South Wales, Australia

2University of Sydney, Dr. John and Anne Chong Lab for Functional Genomics, Camperdown, New South Wales, Australia

\author{
V2 First published: 23 Jan 2018, 7:99 \\ https://doi.org/10.12688/f1000research.13581.1 \\ Latest published: 16 Oct 2018, 7:99 \\ https://doi.org/10.12688/f1000research.13581.2
}

\section{Abstract}

Background: Paclitaxel-induced peripheral neuropathy is a common and limiting side effect of an approved and effective chemotherapeutic agent. The cause of this nociception is still unknown.

Methods: To uncover the mechanism involved in paclitaxel-induced pain, we developed a Drosophila thermal nociceptive model to show the effects of paclitaxel exposure on third instar larvae.

Results: We found that paclitaxel increases heat nociception in a dose-dependent manner, and at the highest doses also obstructs dendritic repulsion cues.

Conclusions: Our simple system can be applied to identify regulators of chemotherapy-induced pain and may help to eliminate pain-related side-effects of chemotherapy.

\section{Keywords}

Drosophila, fruit fly, paclitaxel, nociception, pain, CIPN

\section{Open Peer Review \\ Approval Status ? \\ 12 \\ 23 \\ version 2 \\ (revision) \\ 16 Oct 2018 \\ version 1

$\checkmark$
view

1. Adam Claridge-Chang (iD), Institute of Molecular and Cell Biology (IMCB), Singapore, Singapore

2. Salahadin Abdi, University of Texas MD Anderson Cancer Center, Houston, USA

3. Giorgio Gilestro iD, Imperial College London, London, UK

Any reports and responses or comments on the article can be found at the end of the article. 
Corresponding author: G. Gregory Neely (greg.neely@sydney.edu.au)

Author roles: Hamoudi Z: Conceptualization, Formal Analysis, Investigation, Methodology, Project Administration, Supervision, Visualization, Writing - Original Draft Preparation, Writing - Review \& Editing; Khuong TM: Formal Analysis, Investigation, Writing Original Draft Preparation; Cole T: Formal Analysis, Methodology; Neely GG: Conceptualization, Funding Acquisition, Methodology, Project Administration, Supervision, Writing - Review \& Editing

Competing interests: No competing interests were disclosed.

Grant information: This work was supported in part through NHMRC project grants APP1026310, APP1029672, APP1028887, APP1046090, APP1042416, APP1086851, and by a NHMRC career development fellowship II CDF1111940.

The funders had no role in study design, data collection and analysis, decision to publish, or preparation of the manuscript.

Copyright: (c) 2018 Hamoudi $Z$ et al. This is an open access article distributed under the terms of the Creative Commons Attribution License, which permits unrestricted use, distribution, and reproduction in any medium, provided the original work is properly cited. Data associated with the article are available under the terms of the Creative Commons Zero "No rights reserved" data waiver (CC0 1.0 Public domain dedication).

How to cite this article: Hamoudi Z, Khuong TM, Cole T and Neely GG. A fruit fly model for studying paclitaxel-induced peripheral neuropathy and hyperalgesia [version 2; peer review: 2 approved, 1 approved with reservations] F1000Research 2018, 7:99 https://doi.org/10.12688/f1000research.13581.2

First published: 23 Jan 2018, 7:99 https://doi.org/10.12688/f1000research.13581.1 


\section{REVISED Amendments from Version 1}

This version of the article was revised to include new data on the effect of paclitaxel exposure on the morphology of peripheral pain sensing neurons. In version 1, we did this by dissecting, fixing and mounting the larvae, followed by confocal microscopy and image analysis (Figure 2). However, the dissection method masked the intricate structural changes and we did not see a difference between paclitaxel treatment and vehicle control. In version 2, we instead used live confocal microscopy, and we found that paclitaxel obstructs dendritic repulsion cues at the highest doses (updated Figure 2).

Moreover, in this version, we have addressed the reviewer's comments and also updated all the figure to include all the data points.

See referee reports

\section{Introduction}

Chemotherapy-induced peripheral neuropathy (CIPN) is a dose-limiting side effect of many effective cancer treatments (Burton et al., 2007), and can have a lasting impact on the quality of life of cancer survivors (Hausheer et al., 2006 and Shimozuma et al., 2012). A meta-analysis of 31 studies from over 4000 chemotherapy-treated patients revealed that CIPN was prevalent in $68.1 \%$ of patients in the first month following chemotherapy, in $60 \%$ of patients at 3 months, and in $30 \%$ at 6 months or more (Seretny et al., 2014).

Paclitaxel has a potent ability to cause CIPN (Addington \& Freimer, 2016; Reyes-Gibby et al., 2009). Derived from the bark of the western yew, Taxus brevifolia, it is an approved and effective treatment against breast, ovarian, lung and Kaposi sarcoma (Chang et al., 1993; Gill et al., 1999; Holmes et al., 1991; McGuire et al., 1989; Wani et al., 1971). Patients treated with paclitaxel experience side effects as early as one to three days following treatment (Lipton et al., 1989; Reyes-Gibby et al., 2009). Common symptoms are hyperalgesia, hypoalgesia, allodynia, tingling, numbness, and shooting pain (Boland et al., 2010). Paclitaxel has a direct effect on Schwann cells, promotes axonal degeneration, and can cause mitochondrial damage (André et al., 2000; Cavaletti et al., 1995; Sahenk et al., 1994), however the molecular mechanisms causing pain are still largely unknown.

While much knowledge has been gained about the genetics of pain from vertebrate systems, high-throughput dissection of pain is possible using the fruit fly Drosophila melanogaster (Neely et al., 2010). When challenged with a noxious thermal stimulus, third instar larvae exhibit an aversive escape response that has been utilised to identify conserved genes required for nociception (Babcock et al., 2009; Neely et al., 2010; Tracey et al., 2003). This nociceptive response is a result of activating class IV multidendritic-dendritic arborisation (md-da) sensory neurons at the site of stimulation (Hwang et al., 2007). Previously in Drosophila, paclitaxel has been reported to be toxic in somatic cells, and causes loss of axons in peripheral nerves. (Bhattacharya et al., 2012; Cunha et al., 2001). However, its effects on nociception have not yet been evaluated. Here, we examined the effects of paclitaxel exposure on the fruit fly larval nociception system, and observed a robust and dosedependent increase in pain perception. This system is amenable to high throughput screening and genetic manipulation (Honjo, et al., 2016), and may help define why chemotherapies such as paclitaxel cause pain.

\section{Methods}

Drosophila treatment

All flies were reared at $25^{\circ} \mathrm{C}$ and $65 \%$ humidity over a 12-hour light-dark cycle. Six female and two male Canton $S$ Drosophila melanogaster were mated on food medium (5.4\% sucrose, $3.6 \%$ yeast, $1 \%$ agar, $1.2 \%$ nipagin, and $0.6 \%$ propionic acid) treated with ethanol (vehicle), $0 \mu \mathrm{M}, 0.1 \mu \mathrm{M}, 0.5 \mu \mathrm{M}, 2.5 \mu \mathrm{M}$, $5 \mu \mathrm{M}$ or $10 \mu \mathrm{M}$ paclitaxel (Taxol®; Catalog No. A4393) purchased from ApexBio (Houston, USA). A stock of $1000 \mu \mathrm{M}$ paclitaxel in ethanol was prepared and diluted in food medium accordingly to create the different drug concentrated food. F0 Flies were discarded two days after mating and F1 larvae were left to grow for another three days. On the sixth day, early third instar were collected to assess nociception or dendritic morphology.

\section{Behavioural assay}

For the thermal nociceptive assay (Tracey et al., 2003), distilled water was added to experimental vials to soften the food and release the foraging third instar larvae. The softened, liquid food was then passed through mesh to catch the larvae to be transferred to a $100 \mathrm{~mm}$ petri dish sprayed with distilled water. The larvae were touched laterally on abdominal segments four to six with a heat probe (soldering iron with narrow tip) set to $42^{\circ} \mathrm{C}$ or $46^{\circ} \mathrm{C}$. The rolling response was measured in seconds with a cut-off of 10 seconds. For each drug concentration, five repeats were performed, with 30-40 larvae per repeat.

\section{Live confocal microscopy and image analysis}

Third instar larvae (ppk-Gal4,20xUAS-mCD8-GFP) were collected, washed, and placed dorsal side up on a microscope slide, immobilized in 1:5 (v/v) diethyl ether to halocarbon oil and covered with a $22 \times 50 \mathrm{~mm}$ glass coverslip (Das et al., 2017). A Nikon C2 Confocal microscope was used to image GFPexpressing class IV md-da sensory neurons at abdominal segment 2 (A2), under a 20x magnification. Images of Z-stack sections were captured at $1024 \times 1024$ pixel resolution and representative images were captured at $2048 \times 2048$ pixel resolution, both with $2 \mathrm{x}$ averaging. Z-stack images were converted to maximum intensity projection using ImageJ and automated Sholl analysis was performed on these images. Terminal branches were counted manually. 13 animals were imaged for each treatment. All experiments were conducted in a blinded manner.

\section{Statistical analysis}

Data represent mean \pm SEM and are compared to vehicle control. Analysis was done using GraphPad Prism 5. Statistical analysis for response time was done using Krustal-Wallis, followed by Dunn's pairwise test for multiple comparisons. Statistical analysis for area under the curve mean, terminal branches, 
critical radius and maximum branches was done using Student's $t$-test. n.s. $\mathrm{p}>0.05 .{ }^{*} \mathrm{p}<0.05$. ${ }^{* *} \mathrm{p}<0.01$. ${ }^{* *} \mathrm{p}<0.001$.

\section{Results}

Our goal here was to develop a reproducible paradigm to investigate the effects of paclitaxel on nociception in the fly larvae. Based on previous studies for toxicity (Bhattacharya et al., 2012; Cunha et al., 2001), we selected paclitaxel doses below the lethal limit (Figure 1A), and then tested larval nociception using a heat probe set to a low intensity noxious heat $\left(42^{\circ} \mathrm{C}\right.$; Figure 1B), which is mildly nociceptive to fly larvae (Babcock et al., 2009). Our dose-response study revealed $2.5 \mu \mathrm{M}$ paclitaxel was sufficient to induce significant hyperalgesia, with a maximal hyperalgesia effect observed at $10 \mu \mathrm{M}$ (Figure 1C, $d=0.54$ ). Concentrations higher than $10 \mu \mathrm{M}$ paclitaxel were $100 \%$ lethal (not shown). Paclitaxel did not significantly alter heat nociception latency to a $46^{\circ} \mathrm{C}$ heat stimulus across any of the doses (Figure 1D, $d=0.17$ ). Vehicle (ethanol) control and normal (no ethanol) control showed a response time of $5.71 \mathrm{sec}( \pm 0.23$ SEM; $\mathrm{n}=173)$ and $5.62 \mathrm{sec}( \pm 0.20 \mathrm{SEM}, \mathrm{n}=180$, not shown $)$, respectively $\left(42^{\circ} \mathrm{C}\right.$; Figure $\left.1 \mathrm{E}\right)$. At low concertation's of $0.1 \mu \mathrm{M}$ $(5.21 \mathrm{sec} \pm 0.23 \mathrm{SEM} ; \mathrm{n}=150)$ and $0.5 \mu \mathrm{M}(5.44 \mathrm{sec} \pm 0.26$ SEM; $n=131$ ) paclitaxel did not affect response profiles, however, concentrations of $2.5 \mu \mathrm{M}$ paclitaxel (4.22 sec \pm 0.19 SEM; $\mathrm{n}=180 ; \mathrm{p}<0.001)$ and higher altered response distribution and significantly enhanced nociceptive latency $\left(42^{\circ} \mathrm{C}\right.$; Figure 1E). The fastest latency response was observed at $10 \mu \mathrm{M}$ paclitaxel (3.84 sec \pm 0.24 SEM; $n=140 ; p<0.001)$ with a $36.6 \%$ increase in response time relative to vehicle control (Figure 1C).

To evaluate if paclitaxel exposure caused robust morphological differences in peripheral pain sensing neurons, we fed genetically labelled (ppk-Gal4,20xUAS-mCD8-GFP) larvae paclitaxel and imaged the sensory neuron structure (Figures 2A-B). Treating larvae with $10 \mu \mathrm{M}$ paclitaxel affected its repulsive cues with like neurons, overlapping and forming a closed circular structure (Figure 2B, orange box) compared to vehicle control (Observed in 5 paclitaxel treated animals compared to 0 control animals, Fisher's Exact Test $p<0.05$ ). In some paclitaxel treated larvae we observed very short dendritic arbors with lower GFP intensity (Figure 2B', open arrowhead). This was not observed in vehicle control larvae (Figure 2A'). We next used Sholl analysis to quantify branch distribution with a focus on number of intersections as a function of distance from the cell soma. This revealed increased branching closer to the cell soma in paclitaxel treated larvae compared to control (Figure 2C). Area under the curve (AUC) was also calculated for each animal and mean AUC was also plotted for vehicle control (3894 \pm 122 , $\mathrm{n}=13)$ and $10 \mu \mathrm{M}$ paclitaxel treatment $(4329 \pm 145.7, \mathrm{n}=13)$ (Figure 2D). Treatment with paclitaxel significantly increased the area under the curve compared to vehicle control (Figure 2D, $\mathrm{p}<0.05)$. We also determined maximum branch number and its critical radius and found paclitaxel treatment compared to vehicle control did not have a significant effect on maximum branch number $(62.62 \pm 2.69 ; n=13$ control and $61.28 \pm 2.72$; $\mathrm{n}=13$ paclitaxel $)$ or critical radius $(177.1 \pm 6.78 ; n=13$ control and $192.1 \pm 7.70 ; n=13$ paclitaxel) (Figures 2E-F). Finally, paclitaxel did not significantly affect terminal branch number compared with vehicle control (Figure 2G).
Dataset 1. Larval response time in seconds to $42^{\circ} \mathrm{C}$ heat stimulus http://dx.doi.org/10.5256/f1000research.13581.d191022

Paclitaxel fed larvae were touched with a $42^{\circ} \mathrm{C}$ heat probe and their response time was measured in seconds with a cut-off of 10 seconds. Different treatments were tested: food control, ethanol control, $0.1 \mu \mathrm{M}, 0.5 \mu \mathrm{M}, 2.5 \mu \mathrm{M}, 5 \mu \mathrm{M}$, and $10 \mu \mathrm{M}$ paclitaxel. Five repeats were performed $(n=130-180)$.

Dataset 2. Larval response time in seconds to $46^{\circ} \mathrm{C}$ heat stimulus http://dx.doi.org/10.5256/f1000research.13581.d191023

Paclitaxel fed larvae were touched with a $46^{\circ} \mathrm{C}$ heat probe and their response time was measured in seconds with a cut-off of 10 seconds. Different treatments were tested: food control, ethanol control, $0.1 \mu \mathrm{M}, 0.5 \mu \mathrm{M}, 2.5 \mu \mathrm{M}, 5 \mu \mathrm{M}$, and $10 \mu \mathrm{M}$ paclitaxel. Five repeats were performed $(n=130$ - 180)

\section{Dataset 3. Dendritic morphology of third instar ppk-} Gal4,20xUASmCD8-GFP

http://dx.doi.org/10.5256/f1000research.13581.d222127

Confocal images of vehicle control and $10 \mu \mathrm{M}$ paclitaxel treated larvae. Images represent class IV md-da neurons at abdominal segment A2. Images are at 20x magnification with $2 x$ averaging Scale bar represents $100 \mu \mathrm{m}$.

\section{Discussion}

Here we report a simple, high-throughput genetically tractable system to dissect the mechanisms of CIPN in Drosophila. Some effective and common chemotherapeutic agents such as paclitaxel cause peripheral neuropathy in a dose-dependent manner, limiting its therapeutic potential. Hyperalgesia, hypoalgesia and allodynia are some of the common side effects experienced by patients (Boland et al., 2010). By utilising a conserved hyperalgesia response, we performed a dose-finding study to determine the best drug dose to further investigate mechanisms for how paclitaxel causes pain. Our findings in Drosophila larvae are reminiscent of human patients, where paclitaxel increased pain sensitivity in a dose-dependent manner (Burton et al., 2007).

Drosophila experience a nociceptive response by activation of class IV md-da neurons at the site of stimulation. These neurons form extensive, space filling dendritic arbors that exhibit repulsive characteristics where they do not overlap with neighbouring dendrites but instead terminate projection or make abrupt turns (Grueber et al., 2007). In our system, we found that treatment with paclitaxel obstructs these dendritic guidance cues, leading to an overlap of dendritic arbors. This may be due to paclitaxel's effect on mitotic spindles where it binds to beta-tubulin, stabilizing its polymerization, leading to a disruption of the microtubule organization, and thus impacting microtubule-based dendritic guidance (De Brabander et al., 1981; Parness \& Horwitz, 1981; Rowinsky et al., 1988; Schiff \& Horowitz, 1980). Paclitaxel's unknown neuropathic mechanism may be related to its effects on microtubule function and axonal transport. Our simple system may be used with genomic 
A

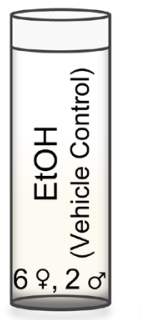

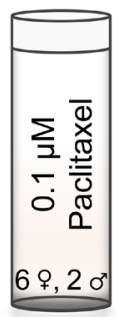

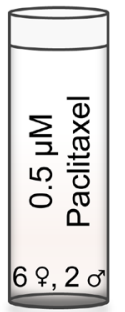

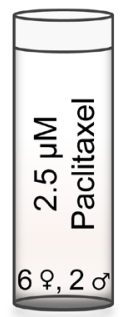

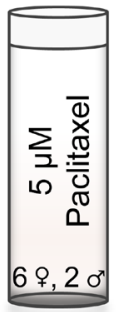

B

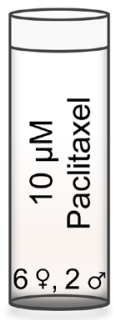

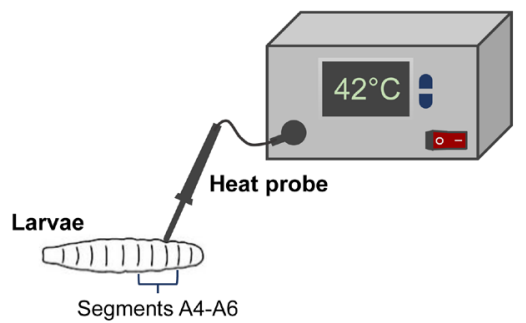

$46^{\circ} \mathrm{C}$

D
C

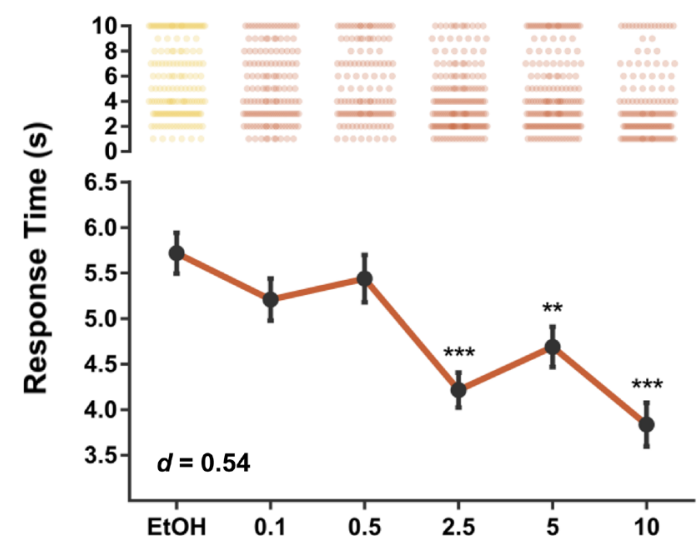

Paclitaxel concentration $(\mu \mathrm{M})$

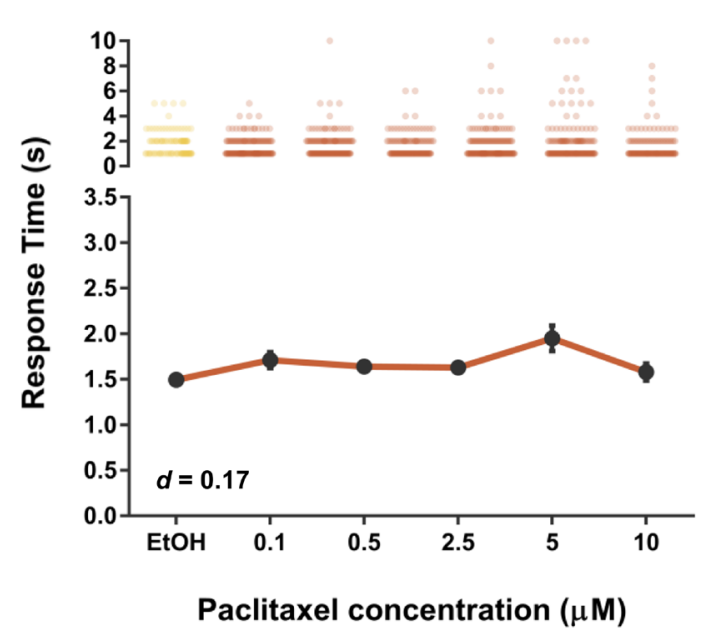

E $42^{\circ} \mathrm{C}$

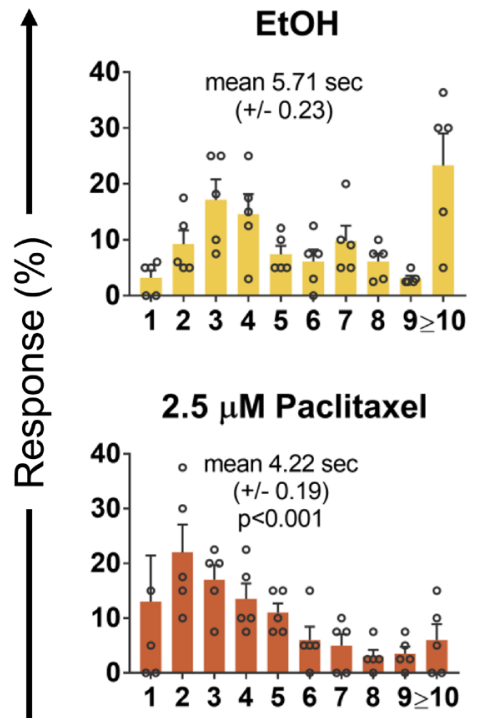

\section{$0.1 \mu \mathrm{M}$ Paclitaxel}
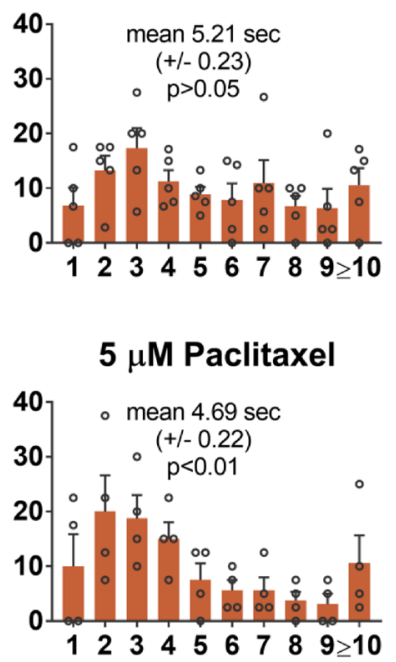

$0.5 \mu \mathrm{M}$ Paclitaxel

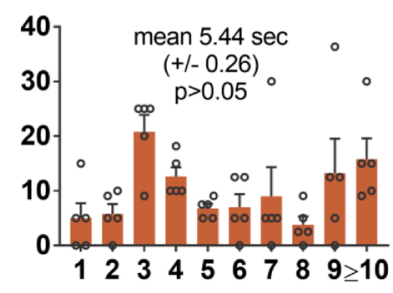

\section{$10 \mu \mathrm{M}$ Paclitaxel}

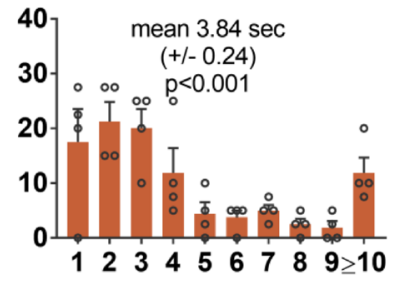

\section{Response Time (s)}

Figure 1. Paclitaxel induces heat-hyperalgesia in Drosophila larvae. Schematic representation of the A) experimental design and B) thermal nociceptive assay in Drosophila larvae. C- D) Average nociceptive latency (in seconds) in response to a $42^{\circ} \mathrm{C}$ or $46^{\circ} \mathrm{C}$ thermal stimulus, respectively. Increased paclitaxel concentration significantly induces heat-hyperalgesia in third instar larvae at $42^{\circ} \mathrm{C}$. Note concentrations higher than $10 \mu \mathrm{M}$ paclitaxel were $100 \%$ lethal. E) Percentage response to each time point in seconds to $42^{\circ} \mathrm{C}$ thermal stimulus. All values represent mean \pm SEM. $p$ values were generated using Krustal-Wallis, followed by Dunn's pairwise test for multiple comparisons. Significance is relative to vehicle control. Five repeats were performed for each drug concentration with roughly 30 larvae each $(n=130-180$ animals). 
A

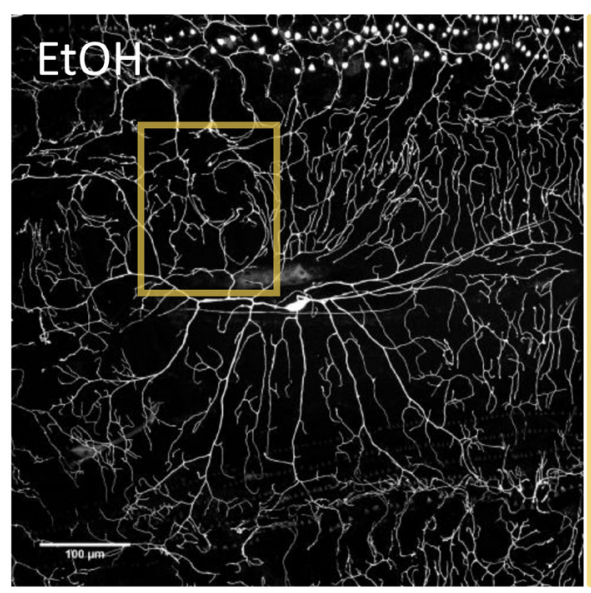

B

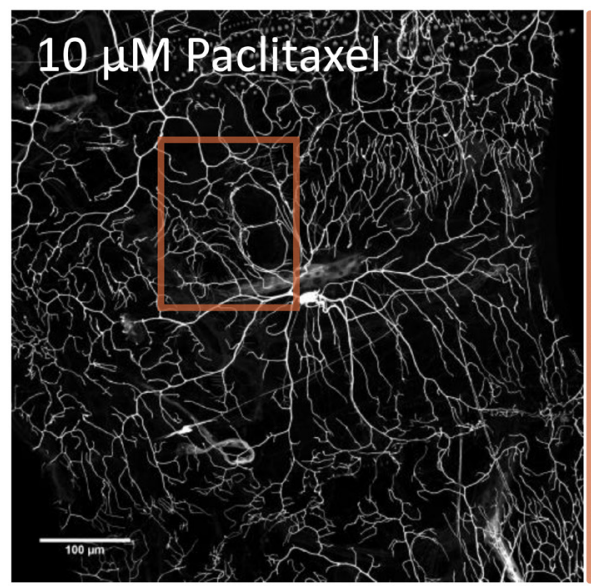

C

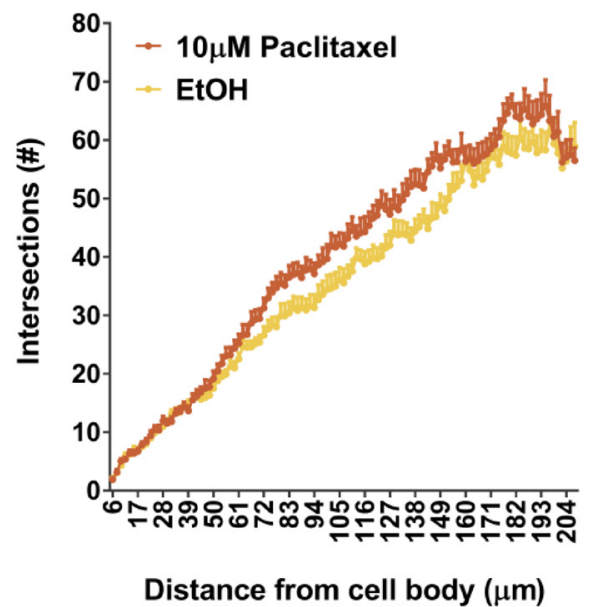

$A^{\prime}$

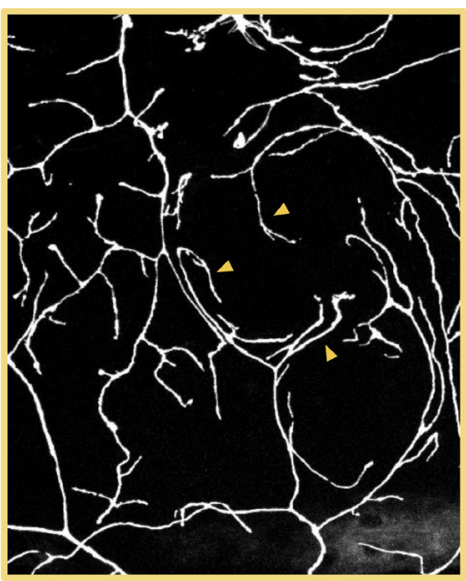

B'

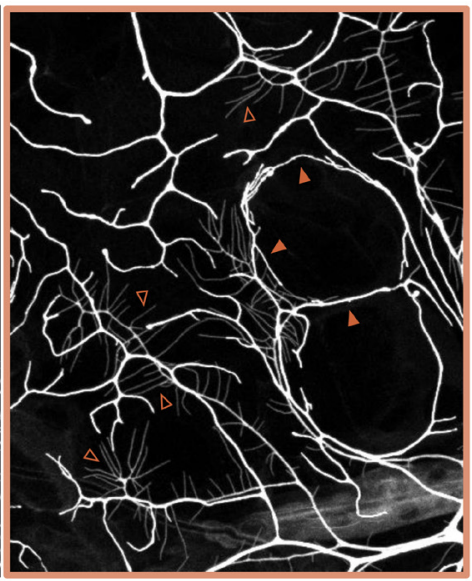

D

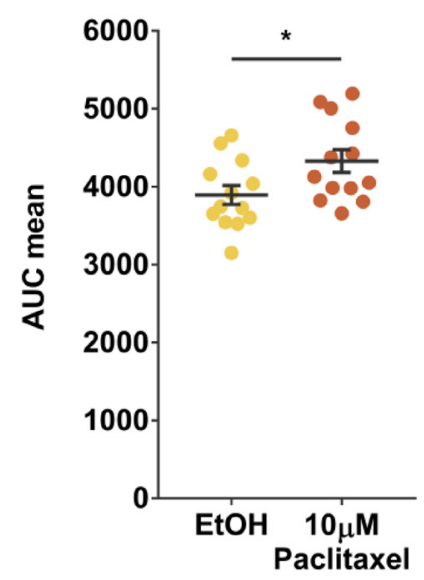

$\mathbf{E}$

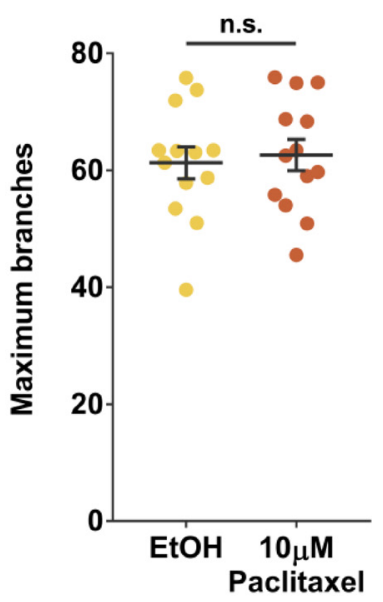

F

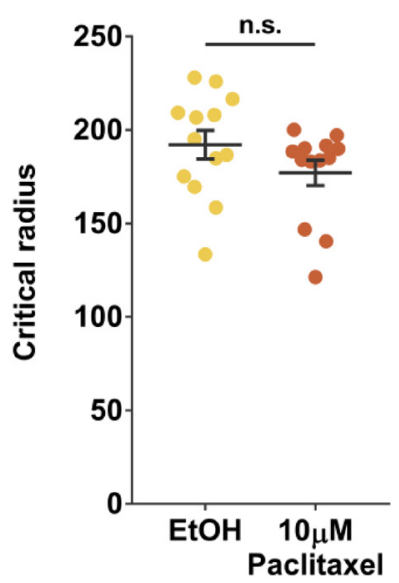

G

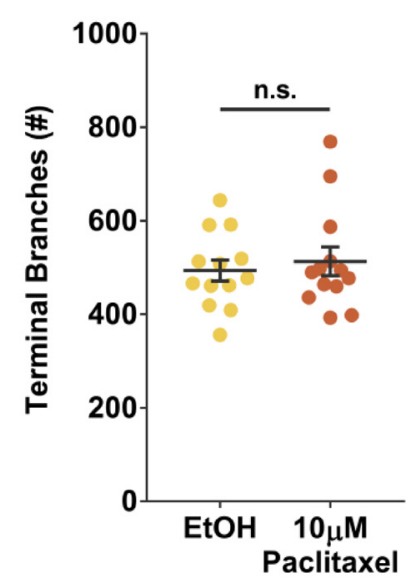

Figure 2. Paclitaxel obstructs dendritic repulsion cues. Representative images (A-B) and quantification (C-G) of ppkGal4,20xUASmCD8-GFP larvae following vehicle control or $10 \mu \mathrm{M}$ paclitaxel treatment. Images are of class IV md-da neurons at abdominal segment A2, under a 20x magnification. Scale bar represents $100 \mu \mathrm{m}$. Paclitaxel treatment obstructs dendritic repulsion cues (B', shaded arrowhead), compared to vehicle control (A'). C) Branch distribution using Sholl analysis. D) Area under the curve. E-F) Maximum branch numbers and critical radius reported by Sholl analysis. G) Branch terminal numbers. Values represent mean \pm SEM $\left(n=13\right.$ animals). n.s. $p>0.05$, t tests and post hoc comparisons: ${ }^{*} p<0.05$. 
approaches to dissect this mechanism and identify regulators of chemotherapy pain. Together this work can lead to a better understanding of how the pain arises, and potentially avoid these severe side effects while more effectively targeting the underlying disease.

\section{Data availability}

Dataset 1: Larval response time in seconds to $42^{\circ} \mathrm{C}$ heat stimulus. Paclitaxel fed larvae were touched with a $42^{\circ} \mathrm{C}$ heat probe and their response time was measured in seconds with a cut-off of 10 seconds. Different treatments were tested: food control, ethanol (vehicle) control, $0.1 \mu \mathrm{M}, 0.5 \mu \mathrm{M}, 2.5 \mu \mathrm{M}$, $5 \mu \mathrm{M}$, and $10 \mu \mathrm{M}$ paclitaxel. Five repeats were performed $(\mathrm{n}=130$ - 180). DOI, 10.5256/f1000research.13581.d191022 (Hamoudi et al., 2018a).

Dataset 2: Larval response time in seconds to $46^{\circ} \mathrm{C}$ heat stimulus. Paclitaxel fed larvae were touched with a $46^{\circ} \mathrm{C}$ heat probe and their response time was measured in seconds with a cut-off of 10 seconds. Different treatments were tested: food control, ethanol (vehicle) control, $0.1 \mu \mathrm{M}, 0.5 \mu \mathrm{M}, 2.5 \mu \mathrm{M}$,
$5 \mu \mathrm{M}$, and $10 \mu \mathrm{M}$ paclitaxel. Five repeats were performed $(\mathrm{n}=130$ - 180). DOI, 10.5256/f1000research.13581.d191023 (Hamoudi et al., 2018b).

Dataset 3: Dendritic morphology of third instar ppkGal4,20xUASmCD8-GFP. Confocal images of vehicle control and $10 \mu \mathrm{M}$ paclitaxel treated larvae. Images represent class IV md-da neurons at abdominal segment A2. Images are at 20x magnification with $2 \mathrm{x}$ averaging. Scale bar represents $100 \mu \mathrm{m}$. DOI, 10.5256/f1000research.13581.d222127 (Hamoudi et al., 2018c).

\section{Grant information}

This work was supported in part through NHMRC project grants APP1026310, APP1029672, APP1028887, APP1046090, APP1042416, APP1086851, and by a NHMRC career development fellowship II CDF1111940.

The funders had no role in study design, data collection and analysis, decision to publish, or preparation of the manuscript.
Addington J, Freimer M: Chemotherapy-induced peripheral neuropathy: an update on the current understanding [version 1; referees: 2 approved]. F1000Res. 2016; 5(F1000 Faculty Rev): 1466. PubMed Abstract | Publisher Full Text | Free Full Text

André N, Braguer D, Brasseur G, et al:: Paclitaxel induces release of cytochrome c from mitochondria isolated from human neuroblastoma cells'. Cancer Res. 2000; 60(19): 5349-53.

PubMed Abstract

Babcock DT, Landry C, Galko MJ: Cytokine signaling mediates UV-induced nociceptive sensitization in Drosophila larvae. Curr Biol. 2009; 19(10): 799-806. PubMed Abstract | Publisher Full Text | Free Full Text

Bhattacharya MR, Gerdts J, Naylor SA, et al:: Taxanes: the genetic toxicity of paclitaxel and docetaxel in somatic cells of Drosophila melanogaster. Mutagenesis. 2012; 16(1): 79-84.

Boland BA, Sherry V, Polomano RC: Chemotherapy-induced peripheral neuropathy in cancer survivors. Oncol Nurse Edn. 2010; 24(2): 33-38, 42-43. Reference Source

Burton AW, Fanciullo GJ, Beasley RD, et al:: Chronic pain in the cancer survivor: a new frontier. Pain Med. 2007; 8(2): 189-198.

PubMed Abstract | Publisher Full Text

Cavaletti G, Tredici G, Braga M, et al.: Experimental peripheral neuropathy induced in adult rats by repeated intraperitoneal administration of taxol. Exp Neurol. 1995; 133(1): 64-72.

PubMed Abstract | Publisher Full Text

Chang AY, Kim K, Glick J, et al.: Phase II study of taxol, merbarone, and piroxantrone in stage IV non-small-cell lung cancer: The Eastern Cooperative Oncology Group Results. J Natl Cancer Inst. 1993; 85(5): 388-94.

PubMed Abstract | Publisher Full Text

Cunha KS, Reguly ML, Graf U, et al.: Taxanes: the genetic toxicity of paclitaxel and docetaxel in somatic cells of Drosophila melanogaster. Mutagenesis. 2001; 16(1): 79-84.

PubMed Abstract | Publisher Full Text

Das R, Bhattacharjee S, Patel AA, et al.: Dendritic Cytoskeletal Architecture Is Modulated by Combinatorial Transcriptional Regulation in Drosophila melanogaster. Genetics. 2017; 207(4): 1401-21.

PubMed Abstract | Publisher Full Text | Free Full Text

De Brabander M, Geuens G, Nuydens R, et al:: Taxol induces the assembly of free microtubules in living cells and blocks the organizing capacity of the centrosomes and kinetochores. Proc Natl Acad Sci U S A. 1981; 78(9): 5608-12. PubMed Abstract | Publisher Full Text | Free Full Text

Gill PS, Tulpule A, Espina BM, et al.: Paclitaxel is safe and effective in the treatment of advanced AIDS-related Kaposi's sarcoma. J Clin Oncol. 1999;
17(6): 1876-83

PubMed Abstract | Publisher Full Text

Grueber WB, Ye B, Yang CH, et al.: Projections of Drosophila multidendritic neurons in the central nervous system: links with peripheral dendrite morphology. Development. 2007; 134(1): 55-64.

PubMed Abstract | Publisher Full Text

Hamoudi Z, Khuong TM, Cole T, et al:: Dataset 1 in: A fruit fly model for studying paclitaxel-induced pain. F1000Research. 2018a.

http://www.doi.org/10.5256/f1000research.13581.d191022

Hamoudi Z, Khuong TM, Cole T, et al.: Dataset 2 in: A fruit fly model for studying paclitaxel-induced pain. F1000Research $2018 \mathrm{~b}$

http://www.doi.org/10.5256/f1000research.13581.d191023

Hamoudi Z, Khuong TM, Cole T, et al.: Dataset 3 in: A fruit fly model for studying paclitaxel-induced pain. F1000Research. 2018c.

http://www.doi.org/10.5256/f1000research.13581.d222127

Hausheer FH, Schilsky RL, Bain S, et al:: Diagnosis, management, and evaluation of chemotherapy-induced peripheral neuropathy. Semin Oncol. 2006; 33(1): 15-49.

PubMed Abstract | Publisher Full Text

Holmes FA, Walters RS, Theriault RL, et al:: Phase II trial of taxol, an active drug in the treatment of metastatic breast cancer. J Natl Cancer Inst. 1991; 83(24): $1797-805$

PubMed Abstract | Publisher Full Text

Honjo K, Mauthner SE, Wang Y, et al:: Nociceptor-Enriched Genes Required for Normal Thermal Nociception. Cell Rep. 2016; 16(2): 295-303.

PubMed Abstract | Publisher Full Text | Free Full Text

Hwang RY, Zhong L, Xu Y, et al:: Nociceptive neurons protect Drosophila larvae from parasitoid wasps. Curr Biol. 2007; 17(24): 2105-2116.

PubMed Abstract | Publisher Full Text | Free Full Text

Lipton RB, Apfel SC, Dutcher JP, et al.: Taxol produces a predominantly sensory neuropathy. Neurology. 1989; 39(3): 368-373.

PubMed Abstract | Publisher Full Text

McGuire WP, Rowinsky EK, Rosenshein NB, et al:: Taxol: a unique antineoplastic agent with significant activity in advanced ovarian epithelial neoplasms. Ann Intern Med. 1989; 111(4): 273-9.

PubMed Abstract | Publisher Full Text

Neely GG, Hess A, Costigan M, et al.: A genome-wide Drosophila screen for heat nociception identifies $\alpha 2 \delta 3$ as an evolutionarily conserved pain gene. Cell. 2010; 143(4): 628-638.

PubMed Abstract | Publisher Full Text | Free Full Text

Parness J, Horwitz SB: Taxol binds to polymerized tubulin in vitro. J Cell Biol. 
1981; 91(2 Pt 1): 479-87.

PubMed Abstract | Publisher Full Text | Free Full Text

Reyes-Gibby CC, Morrow PK, Buzdar A, et al:: Chemotherapy-induced peripheral neuropathy as a predictor of neuropathic pain in breast cancer patients previously treated with paclitaxel. J Pain. 2009; 10(11): 1146-50.

PubMed Abstract | Publisher Full Text | Free Full Text

Rowinsky EK, Donehower RC, Jones RJ, et al:: Microtubule changes and cytotoxicity in leukemic cell lines treated with taxol. Cancer Res. 1988; 48(14): 4093-4100. PubMed Abstract

Sahenk Z, Barohn R, New P, et al.: Taxol neuropathy. Electrodiagnostic and sural nerve biopsy findings. Arch Neurol. 1994; 51(7): 726-729. PubMed Abstract | Publisher Full Text

Schiff PB, Horwitz SB: Taxol stabilizes microtubules in mouse fibroblast cells. Proc Natl Acad Sci U S A. 1980; 77(3): 1561-5.

PubMed Abstract | Publisher Full Text | Free Full Text
Seretny M, Currie GL, Sena ES, et al:: Incidence, prevalence, and predictors of chemotherapy-induced peripheral neuropathy: A systematic review and metaanalysis. Pain. 2014; 155(12): 2461-70.

PubMed Abstract | Publisher Full Text

Shimozuma K, Ohashi Y, Takeuchi A, et al:: Taxane-induced peripheral

neuropathy and health-related quality of life in postoperative breast cance patients undergoing adjuvant chemotherapy: $\mathrm{N}-\mathrm{SAS} \mathrm{BC} 02$, a randomized clinical trial. Support Care Cancer. 2012; 20(12): 3355-64.

PubMed Abstract | Publisher Full Text

Tracey WD Jr, Wilson RI, Laurent G, et al:: painless, a Drosophila gene essential for nociception. Cell. 2003; 113(2): 261-73.

PubMed Abstract | Publisher Full Text

Wani MC, Taylor HL, Wall ME, et al.: Plant antitumor agents. VI. The isolation and structure of taxol, a novel antileukemic and antitumor agent from Taxus brevifolia. J Am Chem Soc. 1971; 93(9): 2325-7.

PubMed Abstract | Publisher Full Tex 


\section{Open Peer Review}

\section{Current Peer Review Status:}

\section{Version 2}

Reviewer Report 04 March 2019

https://doi.org/10.5256/f1000research.18043.r43411

(C) 2019 Gilestro G. This is an open access peer review report distributed under the terms of the Creative Commons Attribution License, which permits unrestricted use, distribution, and reproduction in any medium, provided the original work is properly cited.

\section{Giorgio Gilestro}

Department of Life Sciences, Imperial College London, London, UK

In this work, Hamoudi et al. present the use of Drosophila larvae as a potential biological in-vivo model to study chemotherapy-induced peripheral neuropathy. The work is solid and well presented. The data are convincing and the methods well explained.

I found only two aspects of the work that are perhaps overlooked and could use a couple of notes in the discussion:

1. The work focuses on the effects of only one drug. The title appropriately refers to paclitaxel indeed, but it would be interesting to speculate on whether we could expect the same response using other drugs too.

2. Larvae are developing organisms. Their neuronal network changes as they grow from instar to instar. CIPN, on the other hand, is normally observed in post-developmental conditions. Can we assume that the changes in synaptic structures reported in figure 2 would be observed in a fully developed nervous system too?

I think adding a couple of lines of speculation regarding point 1 and 2 would strengthen the paper.

Is the work clearly and accurately presented and does it cite the current literature? Yes

Is the study design appropriate and is the work technically sound? Yes

Are sufficient details of methods and analysis provided to allow replication by others? Yes

If applicable, is the statistical analysis and its interpretation appropriate? Yes

Are all the source data underlying the results available to ensure full reproducibility? 
Yes

Are the conclusions drawn adequately supported by the results?

Yes

Competing Interests: No competing interests were disclosed.

Reviewer Expertise: Drosophila behaviour and sleep

I confirm that I have read this submission and believe that I have an appropriate level of expertise to confirm that it is of an acceptable scientific standard.

\section{Version 1}

Reviewer Report 22 March 2018

https://doi.org/10.5256/f1000research.14752.r30145

(C) 2018 Abdi S. This is an open access peer review report distributed under the terms of the Creative Commons Attribution License, which permits unrestricted use, distribution, and reproduction in any medium, provided the original work is properly cited.

\section{Salahadin Abdi}

Department of Pain Medicine, Division of Anesthesiology and Critical Care, University of Texas MD Anderson Cancer Center, Houston, TX, USA

This study examined the effects of Paclitaxel exposure on Drosophila larval nociception system and the authors propose that their model is suitable for high throughput screening and further mechanistic studies. The study is overall an interesting and clearly written, however, I do have the following concerns:

1. The dose response effect of thermal stimulation was only at 42 degrees. There was no discussion or explanation why this effect was not seen at 46 degrees.

2. The behavior experiment was based on thermal stimulation. I would be interested why mechanical stimulation was not chosen since mechanical sensitivity is common among patients who develop Paclitaxel induced peripheral neuropathy?

3. It is not clear to me what the timeline is between the exposure of the larvae with paclitaxel and performing microscopic studies.

4. There should be at least a short discussion about the result.

Is the work clearly and accurately presented and does it cite the current literature? Yes

Is the study design appropriate and is the work technically sound?

Yes

Are sufficient details of methods and analysis provided to allow replication by others? 
Partly

If applicable, is the statistical analysis and its interpretation appropriate?

I cannot comment. A qualified statistician is required.

Are all the source data underlying the results available to ensure full reproducibility? Yes

Are the conclusions drawn adequately supported by the results?

Partly

Competing Interests: No competing interests were disclosed.

I confirm that I have read this submission and believe that I have an appropriate level of expertise to confirm that it is of an acceptable scientific standard, however I have significant reservations, as outlined above.

Author Response 09 Oct 2018

Greg Neely, Charles Perkins Centre and School of Life and Environmental Sciences, Camperdown, New South Wales, Australia

Thank you for your comments.

Response to comment \#1: This effect is not seen at $46^{\circ} \mathrm{C}$. At this temperature intensity, larvae respond rapidly ( 1.5 seconds) and it is difficult to see even faster responses. To look for hyperalgesia, we instead lowered the heat stimulus intensity to $42^{\circ} \mathrm{C}$, which is at the threshold for nociception in this system, and where nociceptive responses take on average $\sim 5$ seconds to elicit.

Response to comment \#2: The type IV multidendritic nociceptor neurons that transduce heat nociception also transduce mechanical nociception, as these neurons are multimodal. We have tried on numerous occasions to generate reproducible data for mechanical nociception but so far in our hands this assay does not work well enough for us to feel comfortable publishing. Given the multimodal nature of type IV multidendritic nociceptor neurons, we reasoned that thermal hyperalgesia is a good readout for the overall sensitization of these sensory neurons.

Response to comment \#3: The animals are born into paclitaxel containing food, and then early third instar are collected at day 6 to assess nociception or dendritic morphology. This information was provided in the methods, however we have further clarified this aspect.

Response to comment \#4: We have now written a short discussion, please see discussion section.

Competing Interests: No competing interests were disclosed. 
Reviewer Report 01 March 2018

https://doi.org/10.5256/f1000research.14752.r30150

(C) 2018 Claridge-Chang A. This is an open access peer review report distributed under the terms of the Creative Commons Attribution License, which permits unrestricted use, distribution, and reproduction in any medium, provided the original work is properly cited.

\section{Adam Claridge-Chang}

Institute of Molecular and Cell Biology (IMCB), Singapore, Singapore

The authors characterize the thermal nociception in Drosophila larvae that have been cultured on a range of paclitaxel concentrations. Using a heat probe to elicit the rolling defense behavior, they find that while paclitaxel has no effect on response times with a $46^{\circ} \mathrm{C}$ probe, it shortens probe response times when the larvae have been grown on $2.5 \mu \mathrm{m}$ paclitaxel or above.

The authors and readers might like to consider the following comments on and questions about the 23 Jan 2018 version.

1. The Title describes a model for studying paclitaxel-induced pain, however the assay uses a heat probe to induce pain, and paclitaxel lowers the sensitivity to the probe, thus modeling the hyperalgesia component of paclitaxel CIPN. Would the Title better serve the reader if edited to focus on this side-effect specifically?

2. In Abstract-Results, the authors write: "We found that paclitaxel increases pain perception in a dose-dependent manner, without overt morphological changes." Changing "perception" to "sensitivity" would eliminate the baggage of the former word.

3. In Abstract-Conclusions: "Our simple, high throughput model can be combined with genomics approaches to identify regulators of chemotherapy-induced pain to eliminate its adverse side effects." However, they have not established that this is high-throughput by most common definitions of the term, nor do they show anywhere in the paper that it can be combined with genomics. The Conclusions would be improved if rephrased to better reflect what the data show.

4. "High-throughput" is a phrasal adjective that requires a hyphen.

5. In Introduction it says "This system is amenable to high throughput screening" however, this is not shown in the present manuscript nor is a reference cited in support of the statement.

6. "Krustal-Wallis ANOVA." Correct to "Kruskal-Wallis."

7. I encourage the authors to use estimation statistics instead of significance testing. This would involve presenting and discussing the effect sizes. For example, in Figure 1c, it looks like $2.5 \mu \mathrm{m}$ paclitaxel has the effect of reducing response time by $\sim 1.5 \mathrm{~s}$.

8. It would be nice to calculate standardized effect sizes (e.g. Cohen's d) of the paclitaxel effects; this would allow the authors and readers to estimate sample sizes needed for a screen (and thus possible throughput rates).

9. In Results, the authors write "Thus we establish that paclitaxel sensitizes larvae to heat pain via enhancing sensory neuron or higher order nociception, and not via inducing overt morphological changes." Is it true that enhancing sensory neuron or higher-order nociception are the only two alternatives? If not, this sentence should be rephrased.

10. The Conclusions section reads more like an overview of future plans for the assay. Could it 
be rewritten to more closely address the paper's findings?

Is the work clearly and accurately presented and does it cite the current literature? Yes

Is the study design appropriate and is the work technically sound?

Yes

Are sufficient details of methods and analysis provided to allow replication by others? Yes

If applicable, is the statistical analysis and its interpretation appropriate? Partly

Are all the source data underlying the results available to ensure full reproducibility? Yes

Are the conclusions drawn adequately supported by the results?

No

Competing Interests: No competing interests were disclosed.

I confirm that I have read this submission and believe that I have an appropriate level of expertise to confirm that it is of an acceptable scientific standard.

Author Response 09 Oct 2018

Greg Neely, Charles Perkins Centre and School of Life and Environmental Sciences, Camperdown, New South Wales, Australia

Thank you for your comments.

Response to comment \#1: That's a reasonable point. Since first submission, we have new data that shows our model also involves peripheral neuropathy, so taken together, we have updated the title to capture this aspect and address the reviewer's comment. The new title is "A fruit fly model for studying paclitaxel-induced peripheral neuropathy and hyperalgesia". We hope this is acceptable.

Response to comment \#2: Done.

Response to comment \#3: We have revised this section and now state "Our simple system can be applied to identify regulators of chemotherapy-induced pain".

Response to comment \#4: Done.

Response to comment \#5: We have now included a reference for this statement. 
Response to comment \#6: Done.

Response to comment \#7: We thank the reviewers for their comment and we have incorporated the estimation statistics into our analysis and added all the data points.

Response to comment \#8: We have calculated the effect size, added it to the graphs (1C and 1D), and we have now also mentioned this in the results section. Moreover, we have changed the data representation to show all the data points.

Response to comment \#9: Good point, this has been revised as suggested.

Response to comment \#10: We have now added a discussion section.

Competing Interests: No competing interests were disclosed.

The benefits of publishing with F1000Research:

- Your article is published within days, with no editorial bias

- You can publish traditional articles, null/negative results, case reports, data notes and more

- The peer review process is transparent and collaborative

- Your article is indexed in PubMed after passing peer review

- Dedicated customer support at every stage

For pre-submission enquiries, contact research@f1000.com 